\title{
Dispositivos da Análise Institucional para a explicitação da dimensão política das práticas discursivas
}

\author{
Devices of Institutional Analysis to highlight the political dimension of \\ discursive practices \\ Décio ROCHA* \\ Universidade do Estado do Rio de Janeiro (Uerj) \\ Bruno DEUSDARÁ** \\ Universidade do Estado do Rio de Janeiro (Uerj)
}

\begin{abstract}
RESUMO: Neste artigo, experimenta-se a produtividade dos conceitos de implicação e analisador, desenvolvidos no âmbito dos estudos em Análise Institucional, para, em interlocução com uma ótica discursiva, proceder à leitura de textos relativos a episódio ocorrido no Rio de Janeiro em novembro de 2010, a saber, a ocupação do Complexo do Alemão por forças policiais ditas de pacificação. Como córpus, recorreu-se a textos publicados naquela ocasião em jornais de grande circulação - $O$ Globo e Folha de S. Paulo. A inscrição das categorias de tempo e espaço, além de marcas de discurso relatado e de enunciados contendo negação polêmica (DUCROT, 1987) são tomadas como analisadores da dimensão política que se constrói em cada um desses textos. Os resultados alcançados corroboram a importância dos dispositivos escolhidos para análise, que indicam, se não a construção de relações de embate entre os dois enunciadores, pelo menos a presença de sistemas de alianças não coincidentes.
\end{abstract}

PALAVRAS-CHAVE: Análise Institucional. Implicação. Analisador. Dimensão política das práticas discursivas. Complexo do Alemão.

ABSTRACT: In this paper, we test the productivity of the concepts of implication and analyzer, developed in the scope of studies in Institutional Analysis, in order to bring new light to reading texts related to an event which took place in Rio de Janeiro in November 2010: the occupation of Alemão Hill by the so-called pacification police forces. As a corpus, we had recourse to texts published in newspapers of great circulation - $O$ Globo and Folha de S. Paulo. The inscription of the categories of time and space, as well as marks of reported speech and polemic negation (DUCROT, 1987) are taken as analyzers of the political dimension constructed in each of these texts. Results seem to corroborate the importance of the devices chosen for analysis, indicating, if not the construction of clash relations between the two enunciators, at least the presence of mismatched alliance systems.

KEYWORDS: Institutional Analysis. Implication. Analyzer. Political dimension of discursive practices. Alemão Hill.

\footnotetext{
* Professor Associado do Departamento de Estudos da Linguagem e do Programa de Pós-graduação em Letras (ILE), da Universidade do Estado do Rio de Janeiro.

** Professor Adjunto do Departamento de Estudos da Linguagem e dos Programas de Pós-graduação em Letras (ILE) e em Letras e Linguística (FFP), da Universidade do Estado do Rio de Janeiro. O autor agradece à Faperj pela concessão de bolsa do Programa Jovem Cientista do Nosso Estado (Processo $\mathrm{n}^{\circ}$ 21.4710. Edital 06/2015).
} 


\section{Introdução}

Este artigo tem por objetivo discutir um caminho para a apreensão do que poderíamos considerar como "dimensão política" dos textos, segundo uma ótica discursiva. Para fins de maior clareza, adiantamos que, por "dimensão política", entendemos o sistema de alianças construído entre diferentes vozes apreensíveis em um texto, sendo tal sistema responsável por conferir a essas vozes maior ou menor grau de aderência ao plano instituído. Trata-se, conforme argumentaremos na próxima seção, de um modo de investigação do plano político que difere do roteiro hegemônico que tem norteado os debates sobre a matéria nos estudos discursivos, que ora identificam o político nos textos produzidos por instituições situadas em um território reconhecido como pertencente à política, ora o reduzem a mera temática abordada em qualquer outro campo social.

Ao lado da investigação do funcionamento das formas constituídas (temas e instituições), a abordagem do político que aqui propomos opta pelo acompanhamento das forças em embate na construção de posicionamentos. Essa referência ao plano das formas constituídas e ao das forças em jogo na produção social, que entendemos como atualização de uma dimensão política, remete às contribuições da Análise Institucional para a compreensão do social como território de integração de planos em intensa relação de produção simultânea. Ao dialogar com a recusa do achatamento do social ao plano das instituições formadas, deslocamos a linguagem de sua função meramente representacional, com a pretensa vocação de dar a ver o mundo "tal qual ele é", para uma dimensão de intervenção nessa territorialidade em constante produção: nas instituições que promovem a reiteração de suas formas de segmentação - homens e mulheres, pais e filhos, professores e alunos, profissionais e pacientes, agentes e detentos, clientes e vendedores - coabitam relações em constante tensionamento, forças em captura ou em possibilidade de ser de outro modo e que se atualizam no verbal.

Por essa razão, estamos convencidos de que este é um objetivo inadiável (mas não exclusivo) do trabalho do analista do discurso. Nossa abordagem busca conciliar imperativos de duas ordens: qualificar a dinâmica de acesso às forças em constante relação na produção social; conferir ao linguístico um plano de atualização nessa produção social. 
Para empreender nossa análise, trabalhamos com dois textos jornalísticos publicados em 28 de novembro de 2010 que tematizam uma operação militar ocorrida no Complexo do Alemão, na cidade do Rio de Janeiro: uma notícia, publicada em $\mathrm{O}$ Globo (Anexo 1), e um artigo de opinião, publicado na Folha de S. Paulo (Anexo 2). Com o intuito de articular a reflexão proposta e o material selecionado, serão percorridas as seguintes etapas: (i) definir o que entendemos por política; (ii) situar o quadro teórico de base; (iii) definir as circunstâncias em que se deu o evento; (iv) proceder, a partir do arranjo singular de cada texto, ao levantamento de marcas linguísticas que evidenciem as vozes em aliança; (v) confrontar os sistemas de aliança reconhecidos em cada texto.

\section{O político: sobre implicações e analisadores, num diálogo entre Análise institucional e Análise do discurso}

Desde seus gestos inaugurais, os estudos discursivos têm manifestado interesse em explorar o funcionamento de discursos que tematizam a política em uma das duas seguintes acepções: a política como campo que se delimita em correspondência com certa territorialidade da organização social; a política como temática trabalhada por discursos oriundos de outros campos da vida social, a exemplo dos textos midiáticos ou científicos sobre o tema. Em ambos os usos do termo, consideramos que política remete ao plano das formas constituídas, seja ao das instituições que se supõe produtoras de um certo tipo de discurso, como o partido, o sindicato, outras entidades associativas, seja ao dos conteúdos explicitamente trabalhados por instituições pertencentes a outros campos.

Reconhecemos a fragilidade dessas acepções que vêm caracterizando o termo. Afinal, fazer supor na exploração de um tema da política institucional pela mídia empresarial uma relação de exterioridade é mais um efeito de sentido intensamente perseguido do que uma condição anterior de sua inscrição social. A mídia sempre fala da política, recortando atores, privilegiando temas, evidenciando ou ocultando embates, possuindo, por essa razão, uma ação eminentemente... política!

Para desdobrar a questão, propomos, neste texto, uma terceira possibilidade de explorar o sentido de "política" enquanto "dimensão" presente em todos os textos. O que entendemos por "dimensão política" pode ser localizado no paradigma éticoestético-político de inspiração guattariana, pensado para se substituir ao modelo 
científico de pensamento, que Rolnik (1995) define como remetendo à "luta contra as forças em nós que obstruem as nascentes do devir: forças reativas, forças reacionárias" (1995, p. 2). Podemos também defini-lo com Muylaert (s.d.), para quem o político é vetor no qual se evidencia "o confronto entre os modos de subjetivação singulares e os modos preconizados pelas correntes da normatização das práticas e corpos", definição que tem o mérito de introduzir a distância que separa macropolítica e micropolítica:

As Macropolíticas são os territórios visíveis, aquilo que pode ser assinalado inequivocamente no mapa: os partidos políticos, o Estado, as Leis, as classes sociais, os corpos. Ele opera o visível, é o plano das totalizações, dos sujeitos, recortando unidades. A Micropolítica opera intensidades, opera com as alteridades nos campos de força ... (ROLNIK, 2004 ${ }^{1}$, apud MUYLAERT, s.d.).

Assim, percebe-se que a reflexão que ora se trava valoriza um plano de embate entre formas instituídas e forças instituintes na produção do real. Como dizem Deleuze e Guattari (1996, p.90), "tudo é político, mas toda política é ao mesmo tempo macropolítica e micropolítica". De tal constatação surge a necessidade de se colocar em cena a noção de "implicação", que, segundo Rocha e Deusdará (2010), desempenha um papel relevante nas pesquisas situadas no âmbito das ciências humanas e sociais. Tratase de um conceito que, segundo Monceau (2008, p. 21), remete à relação que indivíduos desenvolvem com a instituição e que só pode ser trabalhada coletivamente. A implicação não passa por uma "decisão" do sujeito. Como exemplo, diremos, com Monceau (2008, p. 22), que, para além das críticas que possamos ter em relação à instituição universitária, não podemos decidir se nela estamos ou não implicados, e essas implicações poderão ser de diferentes modalidades: econômicas, ideológicas, organizacionais, materiais ou libidinais.

A reflexão sobre implicação ganha nova feição quando, em 1983, Lourau propõe uma "tipologia" que conduz a um verdadeiro modelo de análise. O autor falará de duas ordens de implicações: as primárias (dentre as quais aquelas que dizem respeito à relação do pesquisador com seu objeto de ação / intervenção e à sua relação com a instituição de pesquisa ou qualquer outra instituição de pertencimento) e as secundárias (implicações sociais, históricas, epistemológicas, além das implicações na escrita ou qualquer outro meio utilizado para expor a pesquisa) (LOURAU, 1988). Em trabalho

\footnotetext{
${ }^{1}$ Conferindo as referências citadas em Muylaert (s.d.), percebemos que a citação de Rolnik refere-se a
} 
posterior (LOURAU, 1994), o autor acrescentou mais um tipo de implicação secundária, referente à escolha de um modo de restituição da análise, que pode se dar, por exemplo, sob a forma de monografia a ser avaliada, analisada coletivamente, divulgada apenas para alguns, publicada, etc.

Todas essas reflexões sobre as implicações levam-nos a concordar que "a questão não é que devamos nos livrar de nossas ideologias, mas tentar analisá-las coletivamente. O verdadeiro trabalho científico deve estar aí." (MONCEAU, 2008, p. 22). Posicionamento que ratifica a lição deixada por Lourau:

El análisis de la implicación no constituye un privilegio, sino al contrario, una dura coerción producida por el lugar que ocupa el intelectual en la división del trabajo, de la qual él es legitimador más o menos consciente. Estar implicado (hacer o aceptar el análisis de mis propias implicaciones) es, en definitiva, admitir que soy objetivado por lo que pretendo objetivar: fenómenos, acontecimientos, grupos, ideas, etc. ${ }^{2}$ (LOURAU, 1980, p. 112)

Todas essas reflexões têm por origem os trabalhos em Análise institucional desenvolvidos na França a partir dos anos 1960. De modo bastante breve, a Análise Institucional pode ser entendida como uma abordagem analítica que tem por objetivo explicitar o não dito, as relações de poder que presidem aos arranjos produzidos no interior de uma organização, que, no cotidiano, acabam por se tornar invisíveis, naturalizados. Eis como é definido por Lourau (apud HESS, 2010) o que está em jogo quando se adota uma perspectiva institucionalista, independentemente da função que se exerça:

Le sociologue, nous dit Lourau, le psychosociologue, le thérapeute, l'éducateur semblent avoir des fonctions précises: révéler l'action sociale, aider les groupes à fonctionner, soigner les malades, former les jeunes. Mais on peut considérer ces différents métiers sociaux sous un angle radicalement nouveau: ce qu'ont en commun ces spécialistes, en tant que professionnels inscrits dans la division du travail, c'est qu'ils interviennent dans telle institution, à la demande de telle institution, au nom de l'ensemble des institutions, et de leur garantie politique, l'État. ${ }^{3}$ (HESS, 2010)

obra datada de 1993 (e não 2004). Ver Rolnik (1993) nas referência deste artigo.

${ }^{2}$ A análise da implicação não constitui um privilégio, mas, ao contrário, uma rígida coerção produzida pelo lugar que ocupa o intelectual na divisão do trabalho, da qual ele é legitimador mais ou menos consciente. Estar implicado (fazer ou aceitar a análise de minhas próprias implicações) é, definitivamente, admitir que sou objetivado por aquilo que pretendo objetivar: fenômenos, acontecimentos, grupos, ideias etc.

${ }^{3}$ O sociólogo, diz-nos Lourau, o psicossociólogo, o terapeuta, o educador parecem ter funções precisas: revelar a ação social, ajudar os grupos a funcionar, cuidar dos doentes, formar os jovens. Mas podem-se considerar esses diferentes ofícios sob um ângulo radicalmente novo: o que esses especialistas têm em comum, enquanto profissionais inscritos na divisão do trabalho, é o fato de intervirem em determinada 
Comprometida, desse modo, com a produção de uma dada conformação de social, a Análise institucional atualiza sua vocação política quando se coloca no cruzamento de uma macropolítica e de uma micropolítica, ou, se preferirmos, quando explora o tema da institucionalização, voltando-se para os embates entre as formas instituídas e as forças instituintes, assim definidas por Hess:

\begin{abstract}
Par instituant, on entendra à la fois la contestation, la capacité d'innovation et en général la pratique politique comme signifiant de la pratique sociale. Dans l'institué, on mettra non seulement l'ordre établi, les valeurs, modes de représentation et d'organisation considérée (sic) comme normaux, mais aussi les procédures habituelles de prévisions (économique, sociale, politique....). ${ }^{4}$ (HESS, 2010)
\end{abstract}

Ainda no âmbito da Análise Institucional queremos aqui recuperar o conceito de "analisador", entendido como “... toda aquella persona, situación, acción, que desconstruye lo instituído de la institución." (BRITO, 2013, p. 18)

Com efeito, se, como dissemos, a instituição tem o poder de nos objetivar, "de cosificarnos dentro de los estatutos y de las funciones ${ }^{\text {“6 }}$ (LOURAU, 1980, p. 156), é o analisador que nos "desobjetivará", que nos restituirá a subjetividade, segundo Lourau (1980, p. 156). Além disso, o analisador cumpre ainda outras importantes funções no que diz respeito à explicitação das formas instituídas, liberando forças voltadas para a desinstitucionalização das relações interpessoais e para a desmaterialização das formas da opressão que se escondem nas forças instituídas (LOURAU, 1980, p. 156).

A aproximação entre os referenciais teóricos da Análise institucional e da Análise do discurso vem anunciar resultados bastante promissores ${ }^{7}$. À guisa de exemplificação, em um trabalho de Análise do discurso, a explicitação de diferentes vozes por meio da presença do discurso relatado, da negação polêmica, dos pressupostos, etc. cumpre um papel comparável ao do analista institucional frente à

\footnotetext{
instituição, a pedido de uma certa instituição, em nome do conjunto das instituições e de sua garantia política, o Estado.

${ }^{4}$ Por instituinte compreende-se simultaneamente a contestação, a capacidade de inovação e, em geral, a prática política como significante da prática social. Por instituído compreenderemos não apenas a ordem estabelecida, os valores, modos de representação e de organização considerados como normais, mas também os procedimentos habituais de previsões (econômica, social, política ...)

5 “.... toda pessoa, situação, ação, que desconstrói o instituído da instituição."

6 "de nos reificar dentro dos estatutos e das funções"

7 Guirado (2009) explorou o espaço de interseção entre Análise institucional e Análise do discurso. Compartilhamos com a autora o projeto de interdisciplinaridade que anima sua empresa, ainda que não priorizemos exatamente as mesmas articulações teórico-metodológicas, e com ela também dividimos o
} 
pluralidade de demandas que ele saberá ouvir sob a encomenda que lhe é feita. Em ambos os casos, trata-se sempre de buscar novas articulações entre produções textuais e produção de uma dada qualidade de social (a saúde nas relações travadas em uma organização, no caso da Análise institucional; o perfil da comunidade de apoio que dá sustentação às produções textuais, em consonância com o conceito de prática discursiva). O que estará incessantemente em jogo será um trabalho de desconstrução de formas instituídas, naturalizadas como tais, para a liberação de forças instituintes, processo que já coloca em cena o debate sobre o plano político, tópico que abordaremos adiante.

\section{Rio de Janeiro: episódio do Complexo do Alemão}

Optamos por explorar, neste artigo, a "dimensão política” subjacente a dois textos que abordam, a partir de posicionamentos distintos, um episódio em que ações militares no Complexo do Alemão são intensamente acompanhadas pela mídia. Na cobertura midiática, as cenas privilegiaram enquadramentos territoriais nos quais se observavam movimentos de avanços das forças militares, seguidos de recuos dos agentes do "crime organizado"s.

A ocupação do conjunto de favelas do Complexo do Alemão, ocorrida em novembro de 2010, foi mais uma ação do projeto de Unidades de Polícia Pacificadora (UPP) iniciado em 2008 pela Secretaria Estadual de Segurança do Rio de Janeiro, que pretende instituir em favelas as chamadas "polícias comunitárias", expressão que pressupõe uma parceria entre a população e a polícia. A versão oficial para esse modo de constituir "políticas públicas" (quase exclusivamente por meio de experiências de policiamento) nas favelas apresenta-o como forma de desarticular quadrilhas que controla(va)m estes territórios como pretensos "estados paralelos". De 2008 a meados de 2015, tem-se registro da instalação de 42 UPPs em comunidades da capital, cujos resultados geram opiniões nada consensuais: segundo o Estado, conseguiu-se pôr fim aos tiroteios, diminuindo-se os índices de violência; por uma ótica crítica, muitas vidas

desejo de construir uma "estratégia de pensamento para intervenções concretas" (GUIRADO, 2009, p. 6), as quais, em nosso caso, se darão no âmbito das práticas discursivas.

${ }^{8}$ Ratificamos a opinião de Barreira e Botelho (2013, p. 117): "o que se convencionou chamar de 'crime organizado' refere-se apenas a um mercado varejista de drogas que, mesmo contando com algum nível de organização, opera de modo fragmentado e rudimentar". 
vêm se perdendo, como o comprovam os 2600 casos de homicídios cometidos por agentes do estado entre novembro de 2008 e meados de 2016; manifestações populares nas ruas, como a de junho de 2013, expressam a insatisfação diante de tal política do governo, que foi bastante incentivada pelo desejo de garantir a segurança pública por ocasião da realização dos jogos olímpicos de 2016.

Propondo uma análise crítica desse processo de ação do Exército no Rio de Janeiro, Barreira e Botelho (2013) remontam à repressão militar da greve dos metalúrgicos da Companhia Siderúrgica Nacional, situada na cidade de Volta Redonda, em 1988. Segundo os autores, “o episódio é uma expressão extemporânea do regime militar, quando o Exército era acionado em nome da 'segurança nacional" (BARREIRA; BOTELHO, 2013, p. 116). No episódio, as forças militares invadiram a Companhia, atirando contra os trabalhadores em greve e levando três deles à morte. A menção a uma expressão "extemporânea do regime militar" se deve, entre outros fatores, ao tratamento violento conferido aos movimentos sociais e organização sindical, período da ditadura.

A partir do início dos anos 1990, outra feição passa a assumir o emprego de forças militares na cidade do Rio de Janeiro: trata-se de operações que visam a um "combate à criminalidade". De acordo com os autores, a cobertura midiática das operações militares confere pouca atenção ao modo como a "criminalidade a ser combatida" se organiza no aparato estatal, "alimentando a estrutura do tráfico, financiando campanhas políticas, impondo domínios territoriais e movimentando fortunas muito superiores aos lucros do comércio de drogas nas favelas" (BARREIRA; BOTELHO, 2013, p. 117). Como se observa, essa perspectiva, concebendo a ação do tráfico nas favelas como um comércio varejista e indicando suas relações com o aparato estatal, polemiza com a versão oficial que sustenta a ação do tráfico nas favelas como um "estado paralelo".

Desse modo, as operações apontam um deslocamento no tipo de combate a ser realizado. Já não se trata mais de repressão à organização sindical, mas a setores dos moradores da cidade que, "em sua maioria, precariamente ligados ao sistema de trabalho e ao consumo de mercadorias [...] deixaram de ser funcionais no patamar econômico atingido pelo 'espetáculo do crescimento" (BARREIRA; BOTELHO, 2013, p. 127). 


\section{Pistas linguísticas apreendidas em sua função de analisadores}

Conforme dissemos anteriormente, voltamo-nos neste artigo para a análise de dois textos publicados em jornais por ocasião do episódio do Complexo do Alemão, no Rio de Janeiro, em 2010. Trata-se de um recorte bastante delimitado, pois nosso objetivo é construir um caminho para a explicitação do político na materialidade verbal e, para tal, recorreremos à noção de "analisador". Como pretendemos reafirmar, traços da materialidade verbal podem funcionar como analisadores que explicitarão a dimensão política dos textos analisados.

As pistas linguísticas a que recorremos como dispositivos - dispositivos que se revelarão excelentes analisadores, conforme veremos - são, certamente, pistas cuja presença em cada um dos textos não pode ser eludida: (i) no texto "Complexo do Alemão está ocupado, diz polícia” (anexo 1), enunciados nos quais se acumulam marcas de tempo e de espaço, com predominância de ênfase nos episódios situados em um passado próximo, além de um uso singular do discurso relatado; (ii) enunciados negativos no texto "Não haverá vencedores" (anexo 2), no qual localizamos 18 ocorrências, das quais 14 incluem-se na categoria "negação polêmica", de Ducrot (1987), e a inscrição do debate feito nos tempos presente e futuro.

\section{1."Vencemos": ufanismo que festeja a competência das forças policiais"}

Um olhar minimamente atento ao texto "Complexo do Alemão está ocupado, diz polícia" é capaz de identificar a insistência em referências temporais e espaciais que vão ritmar toda a sua construção. Publicado no domingo, 28 de novembro, o texto sempre faz referência a eventos ocorridos nesse mesmo dia e na véspera, sábado dia 27. São muitas as marcas de tempo identificadas na narração, sempre apontando para os eventos que tiveram lugar nesses dois dias de ação da polícia.

$\mathrm{O}$ mesmo parece ocorrer com as expressões que remetem às marcas de lugar: procede-se à descrição do local do evento - o Complexo do Alemão - o mais exaustivamente possível, conforme se verifica em expressões que apontam para as

\footnotetext{
${ }^{9}$ Para facilitar a localização dos trechos submetidos à análise do anexo 1, utilizamos o seguinte critério: as marcas de tempo foram sublinhadas; as marcas de espaço receberam sublinhado duplo; o tracejado destaca os trechos em que se apresenta a captação de vozes em discurso relatado.
} 
formas de ação ainda necessárias, a exemplo da "operação de varredura de casa a casa" e da inspeção de "beco por beco".

A tais marcas de tempo e de espaço bastante pontuais - todas localizadas num "aqui" (Complexo do Alemão) e num "agora” (neste fim de semana) - vêm se somar as ocorrências de verbos no tempo passado. Fala-se, com efeito, de um momento e de um local pontuais do passado - o momento da vitória sobre o inimigo: "Vencemos", "não tivemos dificuldade", “os blindados fizeram o seu papel”, “o Exército realizou vários bloqueios", etc. Neste cenário de vitória já certa, o que se relata no presente como ação ainda por realizar não passa de mero complemento: "Aggora é trabalho de busca", "Os veículos que bloqueavam a entrada da favela estão sendo rebocados”.

Uma outra marca linguística importante para delinear as forças em ação neste cenário - e, como veremos, não nos referimos aqui exclusivamente às forças militares é o discurso relatado. A atualização de tal dispositivo linguístico que permite a inscrição de outra(s) voz(es) no texto jornalístico parece se dar em consonância com um modelo recorrente:

- o enunciador jornalista anuncia o que foi realizado pelas forças policiais: "O

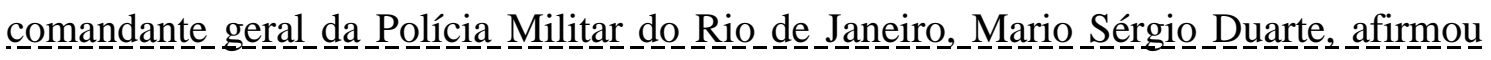
neste domingo que o Complexo do Alemão, na zona norte do Rio, está ocupado".

- o enunciador jornalista passa a palavra às forças policiais para que elas próprias possam enunciar o que foi feito: "Vencemos. Trouxemos liberdade para o povo do Alemão. Agora é trabalho de busca, procura, prisões e apreensões', afirirmou__o D Duarte- em entrevista".

O mesmo parece ocorrer no próximo trecho em que se manifesta o discurso relatado:

. o enunciador jornalista antecipa o ocorrido: "으 comand_ as forças policiais e militares não tiveram muitos problemas no início da invasão".

- a palavra é passada a representante das forças policiais, que enunciará de própria voz o já dito: "Não tivemos dificuldade. Tivemos cobertura dos helicópteros e os blindados fizeram o seu papel', dissse”." 
Acrescentamos ainda uma outra ocorrência de tal procedimento enunciativo, comprovando o papel de "enunciador-oráculo" exercido pelo jornalista, que sempre antecipa o que será dito de viva voz pelas forças policiais:

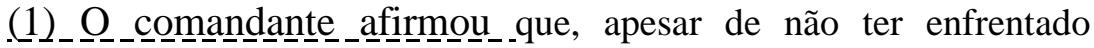
grandes problemas no início da operação, os policiais precisarão

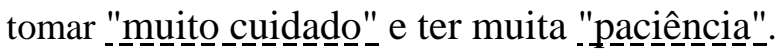

"Agora é hora de paciência, verificar casa por casa, beco por beco, não vai ter um lugar daqui deste complexo que não vai ser verificado, não vai ser checado", disse [o comandante].

A afinidade é efetivamente grande: não só o enunciador jornalista antecipa o "grande feito" realizado pela polícia, como ainda lhe toma de empréstimo algumas de suas palavras, num projeto de construção de uma "enunciação harmoniosa", como podemos perceber, no trecho acima, na escolha dos sintagmas "muito cuidado" e "paciência".

Tal projeto de "enunciação harmoniosa" é ainda reiterado por dois outros índices. O primeiro deles pode ser resumidamente apresentado como se segue: só se recuperam as falas de quem pertence às forças policiais ou de quem com elas colabora. Senão, vejamos os atores citados nominalmente nas diferentes ocorrências de discurso relatado: o comandante geral da Polícia Militar do Rio de Janeiro, Mario Sérgio Duarte; o coronel Lima Castro, relações públicas da PM do Rio; o comandante do Batalhão de Choque, Waldir Soares Filho. Há também a captação da voz das forças policiais de forma genérica, como ocorre em “A Polícia Militar estima que entre 500 e 600 traficantes estariam no Complexo do Alemão" e em "Segundo a Polícia, ele tentou fugir da Vila Cruzeiro".

Uma última categoria de atores que têm direito à fala é formada por aqueles que, não sendo integrantes das forças policiais, dispõem-se a auxiliá-las: “Á_mããe_de _Mister

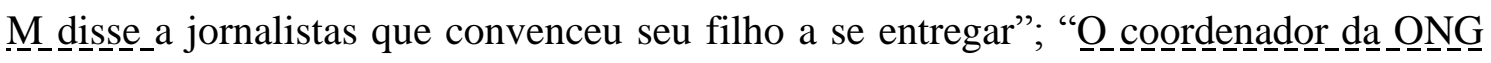
Afrroreggae , José Júnior, esteve no Complexo do Alemão e tentou con_convencer traficantes a se entregarem. [...] Tentei passar pra eles que deveriam se entregar $[\ldots]$ ”.

Quanto ao outro índice de "enunciação harmoniosa" que anunciamos, diremos apenas que diversos fragmentos apresentados como textos do enunciador jornalista só podem ter sido obtidos por meio de uma interlocução com a polícia, o que acaba 
confirmando como muito plausível a hipótese de uma aliança entre o enunciador do texto jornalístico e os diferentes locutores das forças policiais. Com efeito, o enunciador jornalista só pode ter tido conhecimento do quantitativo de militares que tomaram parte na missão, ou do fato de que "no total, 31 pessoas foram detidas e encaminhadas para averiguação", por meio de informações prestadas pela própria polícia.

3.2. "Não haverá vencedores": indignação que se traduz em denúncia ${ }^{10}$

Em "Não haverá vencedores", texto reproduzido no anexo 2, o tempo e o espaço são categorias que se dilatam, e o episódio do Complexo do Alemão passa a reverberar outros momentos já conhecidos de nossa história:

(2) Tem sido assim no Brasil há tempos. Essa lógica da guerra prevalece no Brasil desde Canudos. E nunca proporcionou segurança de fato. Novas crises virão. E novas mortes. [...] É preciso construir mais do que só a solução tópica de uma crise episódica.

A menção feita a Canudos reflete com propriedade o que chamamos aqui de dilatação do episódio. Com efeito, tempo e espaço deixam de se caracterizar como categorias pontuais, como era o caso em 2.1: além de Canudos, o enunciador faz referência a outros momentos da história mundial - o apartheid, o Dia D - como se seu projeto fosse o de apresentar um presente / futuro que não tem fim, que vem se repetindo e continuará o mesmo, pelo menos enquanto a atenção das autoridades estiver voltada para "os bandos do varejo das drogas". O que se faz, então, é a tentativa de desnaturalizar aquilo que se vem construindo como natural: "[o tráfico] existe em todo lugar, no mundo inteiro. E quem leva drogas e armas às favelas? É preciso patrulhar a baía de Guanabara, portos, fronteiras, aeroportos clandestinos."

Apontado o caminho para a necessária atitude crítica de desnaturalização do episódio, o enunciador promove uma crítica ao tipo de narrativa responsável por banalizar a questão: é preciso não apenas desfazer a "narrativa estruturada pelo viés maniqueísta da eterna "guerra" entre o bem e o mal", como também admitir ser "ingenuidade acreditar que confrontos armados nas favelas podem acabar com o crime organizado".

\footnotetext{
${ }^{10}$ Procederemos do mesmo modo já anunciado no subitem anterior: as ocorrências de negação polêmicas estarão sublinhadas no anexo 2; quanto às marcas linguísticas que compreendemos como casos de negação descritiva, usaremos o duplo sublinhado para identificá-las.
} 
As entradas lexicais e as marcas de tempo e lugar até aqui apontadas já indicam em que sentido se constrói o posicionamento político do enunciador: um afastamento em relação ao que constituía a aliança construída pelo enunciador do anexo 1, isto é, em relação às forças policiais. Porém, queremos aqui passar a uma outra marca linguística que funcionará como analisador inequívoco de tal afastamento. Referimo-nos à presença de inúmeros enunciados que se encaixam no que Ducrot (1987) chamou de negação polêmica. Dos 14 enunciados identificados no anexo 2 como manifestações da negação polêmica, transcrevemos aqui 3 para fins de análise:

Exemplo 1: Não haverá vencedores.

Exemplo 2: Não defendem ideologia. Não disputam o Estado.

Exemplo 3: Não há sequer expectativa de vida.

O primeiro enunciado que selecionamos é justamente o título do texto. Sua importância se justifica se for contraposto a um enunciado presente no anexo 1: "Vencemos. Trouxemos liberdade para o povo do Alemão", palavras atribuídas ao comandante geral da Polícia Militar do Rio de Janeiro, Mario Sérgio Duarte. Como se percebe, o enunciado transcrito no exemplo 1 faz abertamente oposição ao proferido pelo comandante da PM. Trata-se de um enunciado negativo que coloca em xeque o enunciador (e, neste caso, locutor ${ }^{11}$ ) representante das forças policiais.

De um modo geral, nos enunciados acima, os exemplos 2 e 3 também colocam em cena enunciadores que poderiam ter alguma familiaridade com o do exemplo 1 , ou seja, enunciadores aliançados às forças policiais. No entanto, os exemplos 2 e 3 parecem de algum modo alargar o perfil desses enunciadores subjacentes aos enunciados negativos. Senão, vejamos: os pontos de vista afirmativos subjacentes a tais enunciados negativos são, respectivamente, "[os jovens pobres e negros que fogem] defendem ideologia e disputam o Estado" e "[para esses mesmos jovens] há expectativa de vida" ${ }^{12}$. Não se poderia dizer que tais pontos de vista sejam sustentados exclusivamente pelas forças policiais. Ao contrário, parece tratar-se de pontos de vista que muito

\footnotetext{
${ }^{11}$ Ducrot atribui a enunciadores (e não a locutores) a responsabilidade de sustentar pontos de vista afirmativos subjacentes aos enunciados com negação polêmica. Entendemos, contudo, que o autor não desqualifique a presença de uma negação polêmica pelo fato de ser possível identificar, além de um enunciador, também um locutor que efetivamente tenha proferido o enunciado afirmativo que possa ser associado a tal negação.

12 Acrescentemos que, em função da presença de "sequer" no enunciado negativo correspondente, depreende-se o pressuposto assumido pelo enunciador de que esses jovens são desprovidos de tudo, até
} 
regularmente são defendidos por governos aliançados com forças retrógradas da sociedade, as quais encontram apoio certo no senso comum.

\subsection{Breves comentários sobre forças em embate no plano textual}

Ao final da análise dos dois textos, o que desejamos iluminar é uma modalidade de embate à qual tivemos acesso, para além de todas as agressões e violências físicas que marca(ra)m a presença das forças policiais no convívio com comunidades como o Complexo do Alemão: o embate entre o enunciador do texto publicado em $O$ Globo, aliançado com as forças estatais, e o enunciador do texto publicado na Folha de $S$. Paulo, em franca oposição às manobras desse Estado. O quadro a seguir reúne índices de oposição entre esses dois enunciadores que sustentam diferentes relações de aliança:

Quadro 1: Posicionamentos discursivos em relação de oposição

\begin{tabular}{|c|c|c|c|}
\hline \multicolumn{2}{|c|}{$\begin{array}{c}\text { Posicionamento de aliança entre enunciador e } \\
\text { forças policiais: } \\
\text { "Vencemos" }\end{array}$} & \multicolumn{2}{|c|}{$\begin{array}{c}\text { Posicionamento de antagonismo entre enunciador e } \\
\text { forças policiais: } \\
\text { "Não haverá vencedores" }\end{array}$} \\
\hline $\begin{array}{l}\text { forças de segurança } \\
\text { governo federal } \\
\text { a sociedade } \\
\text { os policiais } \\
\text { o Bope } \\
5 \text { citações nominais }\end{array}$ & $\begin{array}{l}\text { os criminosos } \\
\text { criminosos ligados } \\
\text { ao tráfico } \\
\text {. os bandidos }\end{array}$ & $\begin{array}{l}\text { forças policiais } \\
\text { o Estado } \\
\text { a polícia } \\
\text {. o aparato bélico do } \\
\text { Estado } \\
\text { a UPPs }\end{array}$ & $\begin{array}{l}\text {. jovens pobres, negros, } \\
\text { armados de fuzis } \\
\text {. os bandos do varejo das } \\
\text { drogas } \\
\text {. os homens armados em } \\
\text { fuga } \\
\text {. "inimigo" }\end{array}$ \\
\hline \multicolumn{2}{|c|}{$\begin{array}{l}\text { Tempo linear: o fato é 'página virada' } \\
\text { Passado }\end{array}$} & \multicolumn{2}{|c|}{$\begin{array}{l}\text { Tempo cíclico: os fatos sempre se repetem } \\
\text { Presente e futuro }\end{array}$} \\
\hline \multicolumn{2}{|c|}{$\begin{array}{l}\text { Espaço espetacularizado: exibição da missão } \\
\text { satisfatoriamente cumprida }\end{array}$} & \multicolumn{2}{|c|}{$\begin{array}{l}\text { Espaço da negação de direitos: [falta] creche, escola, } \\
\text { assistência social, lazer, saneamento; a comunidade é } \\
\text { praça de guerra }\end{array}$} \\
\hline \multicolumn{2}{|c|}{$\begin{array}{l}\text { Política de segurança pública: reconquista } \\
\text { territorial }\end{array}$} & \multicolumn{2}{|c|}{$\begin{array}{l}\text { Falta de vontade política para combater o crime onde } \\
\text { o crime se organiza: onde há poder e dinheiro }\end{array}$} \\
\hline
\end{tabular}

\section{(In)conclusões}

Neste texto, conduzimos uma reflexão a respeito da "dimensão política" em um material que tematiza uma intervenção militar ocorrida no Complexo do Alemão, em 2010. A rigor, tanto o modo como se aborda o referido evento, quanto os atores que são convocados a falar parecem colocar em cena um debate técnico (e, aparentemente, não político!) a respeito de uma operação militar. Não há qualquer avaliação, no primeiro texto, situando tal operação em um conjunto mais amplo de políticas de segurança pública. A autoridade a quem se confere lugar é o comandante da Polícia Militar, 
omitindo-se, por exemplo, falas do secretário de segurança pública ou do governador do estado. Apenas a ação do enunciador do segundo texto traz para o debate polêmicas que questionam as premissas da referida operação.

Como efeitos de sentido observados no primeiro texto, que confirmam tal modo de delineamento dos embates em tela, percebemos que as referências de tempo e de espaço circunscrevem o evento a um momento pontual, cujas explicações e justificativas se naturalizam, em antecipações das falas da autoridade policial na voz do próprio enunciador jornalista. São postos em cena também apenas atores que se propõem a colaborar com a ação policial.

Já no segundo texto, as marcas de negação polêmica parecem evidenciar a emergência de outro debate: desloca-se a atenção dos contornos da "guerra" e do “enfrentamento militar" para estratégias de ação diversificadas que se dilatam no tempo. Desse modo, tanto as marcas de negação polêmica, quanto as coordenadas de tempo e espaço constituem-se como analisadores da ampliação dos contornos da análise proposta.

Entendemos que os dispositivos de análise escolhidos - as marcas linguísticas privilegiadas em cada texto - portaram-se como analisadores muito poderosos, no sentido de explicitarem as alianças / oposições de forças presentes nos textos. A nosso ver, esses analisadores que explicitam relações de força no texto representam uma via de acesso importante ao plano político do episódio, como se observa na construção do quadro em 3.3, que evidencia não um mero debate de versões de um mesmo evento, mas a própria constituição de mundos em divergência.

Do mesmo modo, uma reflexão sobre as implicações poderá colocar em evidência nossa ação enquanto pesquisadores do campo dos estudos do discurso na construção de instrumentos de análise diversos que exponham nossas implicações em uma vertente social das práticas de linguagem, que não apenas passa pela identificação de marcas linguísticas nos textos, mas subjaz à própria definição do córpus de análise, capaz de reconstituir um cenário social de embates e polêmicas.

\section{REFERÊNCIAS}

BARREIRA, M.; BOTELHO, M. L. O Exército nas ruas: da operação Rio à ocupação do Complexo do Alemão. Notas para uma reconstrução da exceção urbana. BRITO, F.; 
OLIVEIRA, P. R. de. Até o último homem: visões cariocas da administração armada da vida social. São Paulo: Boitempo, 2013, p. 115-128.

BRITO, R. M. Introducción a los conceptos básicos del Análisis Institucional. Revista Sujeto, Subjetividad y Cultura, Santiago de Chile, número 5, pp. 6-20, abril 2013. Disponível em: Acesso em: 30/01/2017.

DELEUZE, G.; GUATTARI, F. Mil platôs, vol. 3. Trad. De Aurélio G. Neto et al. Rio de Janeiro: Ed. 34, 1996.

DUCROT, O. $O$ dizer e o dito. Revisão técnica da tradução Eduardo Guimarães. Campinas, SP: Pontes, 1987.

GUIRADO, M. A Análise Institucional do Discurso como analítica da subjetividade. Tese de Livre Docência apresentada ao Departamento de Psicologia da Aprendizagem. Instituto de Psicologia da USP. São Paulo, 2009.

HESS, R. René Lourau et la fondation de l'analyse institutionnelle (3). In: Le blog de Benyounès Bellagnec, 2010. Disponível em: lesanalyseurs.over-blog.org/article-renelourau-et-la-fondation-de-1-analyse-institutionnelle-3-42593003.html. Acesso em: 24 fev. 2017

LOURAU, R. El Estado y el inconsciente. Tradução de David Rosenbaum. Numancia, Barcelona: Kairós, 1980.

Quelques approches de l'implication suivi de "Genèse du concept d'implication". POUR, Paris, n. 88, p.12-27, 1988.

Actes manqués de la recherche. Paris: P.U.F., 1994.

MAINGUENEAU, D. Novas Tendências em Análise do Discurso. Tradução Freda Indursky. Campinas, SP: Pontes, 1989.

MONCEAU, G. Implicação, sobreimplicação e implicação profissional. Fractal Revista de Psicologia, v. 20, n. 1, p. 19-26, jan./jun. 2008.

MUYLAERT, M. A. O Paradigma Ético-Estético-Político e a processual produção da Clínica da Diferença: conceitos para deslocamentos possíveis. s.l., s.d. Disponível em: academia.edu/22810413/O_Paradigma_Ético-Estético-

Político_e_a_processual_Produção_da_Clínica_da_Diferença. Acesso em: 05/02/2017.

ROCHA, D.; DEUSDARÁ, B. Contribuições da Análise institucional para uma abordagem das práticas linguageiras: a noção de implicação na pesquisa de campo. Cadernos de Letras da UFF, Niterói, $\mathrm{n}^{0}$ 40, p. 47-73, 2010. Disponível em: http://www.uff.br/cadernosdeletrasuff/40/artigo2.pdf. Acesso em: 04/02/17.

ROLNIK, S. Pensamento corpo e Devir Uma perspectiva ético/estético/ política no trabalho acadêmico. Cadernos de Subjetividade, São Paulo, v.1 n.2: 241-251. Núcleo de 
Estudos e Pesquisas da Subjetividade, Programa de Estudos Pós Graduados de Psicologia Clínica, PUC/SP. São Paulo, set./fev. 1993.

Ninguém é deleuziano. Entrevista a Lira Neto e Silvio Gadelha. In: O Povo, Caderno Sábado: 06. Fortaleza, 18/11/95. Disponível em: pucsp.br/nucleodesubjetividade/Textos/SUELY/ninguem.pdf. Acesso em: 30 jan. 2016.

\section{ANEXOS}

Anexo 1: $O$ Globo de 28/11/2010, disponível em: noticias.uol.com.br/ultimasnoticias/bbc/2010/11/28/complexo-do-alemao- esta-ocupado-diz-policia.htm

\section{Complexo do Alemão está ocupado, diz polícia}

Invasão no Complexo do Alemão começou na manhã de domingo

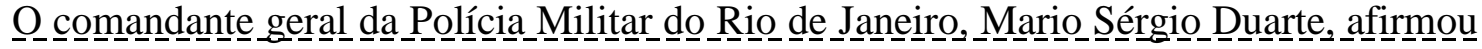
neste domingo que o Complexo do Alemão, na zona norte do Rio, está ocupado.

"Vencemos. Trouxemos liberdade para o povo do Alemão. Agora é trabalho de busca, procura, prisões e apreensões", afirirmo $\underline{\text { u }}$ o__ D

Ainda não está claro se todas as posições de criminosos dentro do complexo de favelas foram tomadas pelas forças policiais e militares envolvidas na operação. $O$ cerco continua nos 44 acessos do complexo e as forças de segurança, que não encontraram muita resistência, iniciaram a operação de varredura casa a casa.

O_comandante da muitos problemas no início da invasão.

"Não tivemos dificuldade. Tivemos cobertura dos helicópteros e os blindados fizeram o seu papel", dissse.

A operação de invasão do Complexo do Alemão, onde estariam centenas de traficantes, começou por volta das $\underline{8 \mathrm{~h} \text { da manhã deste domingo. }}$

No total, participam da invasão 800 soldados da Brigada de Infantaria Paraquedista do Exército, 300 agentes da Polícia Federal (PF) e 1,3 mil homens das polícias Militar e Civil mobilizados para operação no Rio de Janeiro.

Blindados do Exército e da Marinha e veículos do Batalhão de Operações Especiais da PM (Bope) foram utilizados na operação e estão dentro do complexo. A_Polícia $\underline{\text { Militar }}$ estima_a que entre 500 e 600 traficantes estariam no Complexo do Alemão.

Desde o sábado mais de 2 mil homens das forças de segurança já estavam prontos para invadir o complexo de favelas e mantinham um cerco posicionados nos 44 acessos do complexo.

Na manhã deste domingo, uma hora antes do início da invasão, ocorreram tiroteios intensos na região e os homens estavam posicionados aguardando apenas a chegada dos

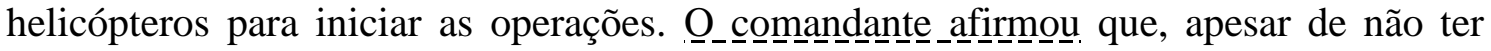
enfrentado grandes problemas no início da operação, os policiais precisarão tomar

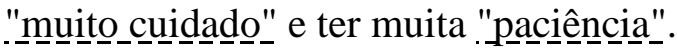

"Agora é hora de paciência, verificar casa por casa, beco por beco, não vai ter um lugar daqui deste complexo que não vai ser verificado, não vai ser checado", dissse. 
D. não significa que o confronto não vai ocorrer.

A polícia já chegou a uma área conhecida como Areal, no centro do Complexo do Alemão. As ruas estão desertas, o comércio fechado e foram apreendidas armas e drogas.

Os veículos que bloqueavam a entrada da favela estão sendo rebocados e, nas ruas, só são vistos carros policiais.

\section{Ultimato}

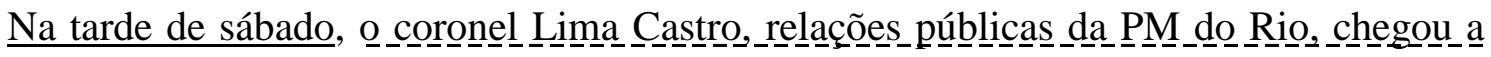
dizer a jornalistas que os traficantes teriam até o por-do-sol para se entregar.

"A proposta é de paz, mas se formos chamados à guerra, vamos responder com a mesma força", a a îrmo-nou.

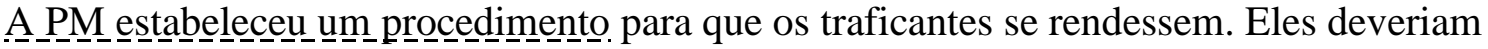
se apresentar com fuzis sobre as cabeças e entregar as armas num posto montado na rua Joaquim Queiroz, no Complexo do Alemão, próximo à Estrada de Itararé.

No domingo, este foi um dos pontos de entrada das forças policiais.

Segundo_ Lima Castro, os bandidos estão "desgastados_e estres_essadosos", sem mantimentos e munição. O_coronel_ afirmono que a superioridade numérica e de equipamento das forças de segurança é total. "Tudo _é favorónével a nó

O__comandante do do Batalhãa todas as pessoas que entram ou saem do Complexo do Alemão estavam sendo revistadas e obrigadas a apresentar documento de identidade.

Veículos militares blindados entraram no Complexo do Alemão pouco depois do início da invasão

Ao longo do dia, o Exército realizou vários bloqueios no Complexo do Alemão, parando e revistando pedestres, carros, motos e caminhões para evitar a fuga de traficantes.

\section{Traficantes detidos}

No total, 31 pessoas foram detidas e encaminhadas para averiguação pela Polícia Civil no sábado.

Entre eles, está Edson Souza Barreto, o "Piloto", 49 anos, chefe de segurança de Fabiano Atanázio, o "FB", chefe do tráfico na Vila Cruzeiro. Segundo tentou fugir da Vila Cruzeiro ao se misturar a um grupo de moradores que descia o morro portando bandeiras brancas.

Já Diego Raimundo Santos, conhecido como "Mister M", se rendeu à Polícia no Morro do Alemão. Ele é suspeito de fazer a segurança do traficante Pezão, que chefia o tráfico

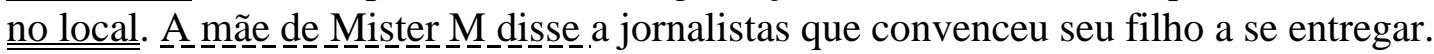

Duas pessoas foram feridas a tiros na região na manhã deste sábado, ao tentar escapar do cerco. Os dois suspeitos foram atendidos em um hospital local e levados à delegacia da região em seguida.

O__coorden_enador_d_a_ON_______froreggae, José Júnior, esteve no Complexo do Alemão e tentou convencencer traficantes a se entregarem.

Ninguém falou que queria partir pro enfrentamento, mas não quer dizer que ninguém vá, afirmou ele ele à imprensa no local ao sair. Tentei pass para que não morressem e também não expusessem os moradores". 
Anexo 2: Folha de S. Paulo, de 28/11/2010 Disponível em: 1.folha.uol.com.br/fsp/opiniao/fz2811201007.htm

\section{TENDÊNCIAS/DEBATES \\ Não haverá vencedores \\ Marcelo Freixo}

\section{Pode parecer repetitivo, mas é isso: uma solução para a segurança pública do Rio terá de passar pela garantia dos direitos dos cidadãos da favela}

Dezenas de jovens pobres, negros, armados de fuzis, marcham em fuga, pelo meio do mato. Não se trata de uma marcha revolucionária, como a cena poderia sugerir em outro tempo

Eles estão com armas nas mãos e as cabeças vazias. Não defendem ideologia. Não disputam o Estado. Não há sequer expectativa de vida. Só conhecem a barbárie. A maioria não concluiu o ensino fundamental e sabe que vai morrer ou ser

presa.

As imagens aéreas na TV, em tempo real, são terríveis: exibem pessoas que tanto podem matar como se tornar cadáveres a qualquer hora. A cena ocorre após a chegada das forças policiais do Estado à Vila Cruzeiro e ao Complexo do Alemão, zona norte do Rio de

Janeiro.

O ideal seria uma rendição, mas isso é difícil de acontecer. O risco de um banho de sangue, sim, é real, porque prevalece na segurança pública a lógica da guerra. O Estado cumpre, assim, o seu papel tradicional. Mas, ao final, não costuma haver vencedores. Esse modelo de enfrentamento não parece eficaz. Prova disso é que, não faz tanto tempo assim, nesta mesma gestão do governo estadual, em 2007, no próprio Complexo do Alemão, a polícia entrou e matou 19. E eis que, agora, a polícia vê a necessidade de entrar na mesma favela novo Tem sido assim no Brasil há tempos. Essa lógica da guerra prevalece no Brasil desde Canudos. E nunca proporcionou segurança de fato. Novas crises virão. E novas mortes. Até quando? Não vai ser um Dia D como esse agora anunciado que vai garantir a paz. Essa analogia à data histórica da $2^{\mathrm{a}}$ Guerra Mundial não passa de fraude midiática. Essa crise se explica, em parte, por uma concepção do papel da polícia que envolve o confronto armado com os bandos do varejo das drogas. Isso nunca vai acabar com o tráfico. Este existe em todo lugar, no mundo inteiro. E quem leva drogas e armas às favelas?

É preciso patrulhar a baía de Guanabara, portos, fronteiras, aeroportos clandestinos. O lucrativo negócio das armas e drogas é máfia internacional. Ingenuidade acreditar que confrontos armados nas favelas podem acabar com o crime organizado. Ter a polícia que mais mata e que mais morre no mundo não resolve. Falta vontade política para valorizar e preparar os policiais para enfrentar o crime onde o crime se organiza - onde há poder e dinheiro. E, na origem da crise, há ainda a desigualdade. É a miséria que se apresenta como pano de fundo no zoom das câmeras de TV. Mas são os homens armados em fuga e o aparato bélico do Estado os protagonistas do impressionante espetáculo, em narrativa estruturada pelo viés maniqueísta da eterna "guerra" entre 0 bem $\quad$ e $\quad 0 \quad$ mal. Como o "inimigo" mora na favela, são seus moradores que sofrem os efeitos colaterais da "guerra", enquanto a crise parece não afetar tanto assim a vida na zona sul, onde a 
ação da polícia se traduziu no aumento do policiamento preventivo. A violência é desigual.

É preciso construir mais do que só a solução tópica de uma crise episódica. Nem nas UPPs se providenciou ainda algo além da ação policial. Falta saúde, creche, escola, assistência social,

lazer.

O poder público não recolhe o lixo nas áreas em que a polícia é instrumento de apartheid. Pode parecer repetitivo, mas é isso: uma solução para a segurança pública terá de passar pela garantia dos direitos básicos dos cidadãos da favela. Da população das favelas, $99 \%$ são pessoas honestas que saem todo dia para trabalhar na fábrica, na rua, na nossa casa, para produzir trabalho, arte e vida. E essa gente - com as suas comunidades tornadas em praças de "guerra"- $\underline{\underline{\text { não }}}$ consegue exercer sequer o direito de dormir em paz. Quem dera houvesse, como nas favelas, só $1 \%$ de criminosos nos parlamentos e no Judiciário...

MARCELO FREIXO, professor de história, deputado estadual (PSOL-RJ), é presidente da Comissão de Defesa dos Direitos Humanos e Cidadania da Assembleia Legislativa do Rio de Janeiro. 